\title{
BIM-technologies for Buildings Operation. Experiment in MGSU.
}

\section{Andrey Volkov ${ }^{1, a}$, Pavel Chelyshkov ${ }^{1, b}$, Artem Sedov $^{1, c}$, Anna Doroshenko ${ }^{1, d^{*}}$ and Denis Lysenko, e}

${ }^{1}$ Moscow state university of civil engineering, 129337, Russia, Moscow, Yaroslavskoe shosse 26

a rector@mgsu.ru, bchelyshkovpd@gmail.com, csedov.eit@gmail.com, dpochta.avd@gmail.com, edenis.lysenko111@gmail.coml

Keywords: Energy-efficient control; Software for automated building management systems; operational control; Life-support systems; Information modelling of construction projects; Engineering simulation; Control of engineering systems; Automated monitoring

\begin{abstract}
This article describes the approach of experts of the National Research Moscow State University of Civil Engineering (MGSU) to the construction of modern operating systems in buildings using BIM-technology. This article was performed within the Russian State task.
\end{abstract}

\section{Introduction}

Since 2008, in National Research Moscow State University of Civil Engineering (MGSU) exist Situational Energy Efficiency Centre of MGSU (SEC MGSU).

Today SEC MGSU provides energy-efficient control of the operation of two buildings with a total area of the University for more than $18000 \mathrm{sq}$. m. Infrastructure SEC MGSU enables operational control of the operation of engineering systems, archiving and analysis of data, verification of the technical and technological solutions and software for automated building management systems (ABMS).

\section{Discussion}

SEC MGSU is the epitome of an experimental platform and a new approach to building - view of the construction of the object throughout the life cycle - from conception to the time of the disposal. This approach involves the development of the concept and design of construction projects according to the conditions and terms of further operation. It allows - for capital construction projects - to achieve substantial savings in operating costs (payment of resources - heat, water, electricity, maintenance costs operation service; the cost of sudden failure of hardware engineering systems due to lack of timely diagnosis, to eliminate the consequences of accidents costs because of lack of engineering safety systems).

Implemented in SEC MGSU system performs the operational management and analytical data processing of all engineering objects of life-support systems: electricity, lighting, heating, heating, ventilation, water supply and sewerage. The quality of the power supply is controlled by 110 points, heat parameters - flow rate and coolant temperature - controlled at 40 points, at 10 points controlled the water flow, traffic control is carried out in 100 points and in 100 points is carried out ambient light control, noise is monitored in 90 points, in 95 points internal air temperature is controlled and at 10 points relative humidity of internal air is controlled. In addition, SEC MGSU is equipped with a weather station, transmitting in the system environmental conditions (ambient air temperature, relative humidity of the outside air, wind speed and direction, the presence of rain). 


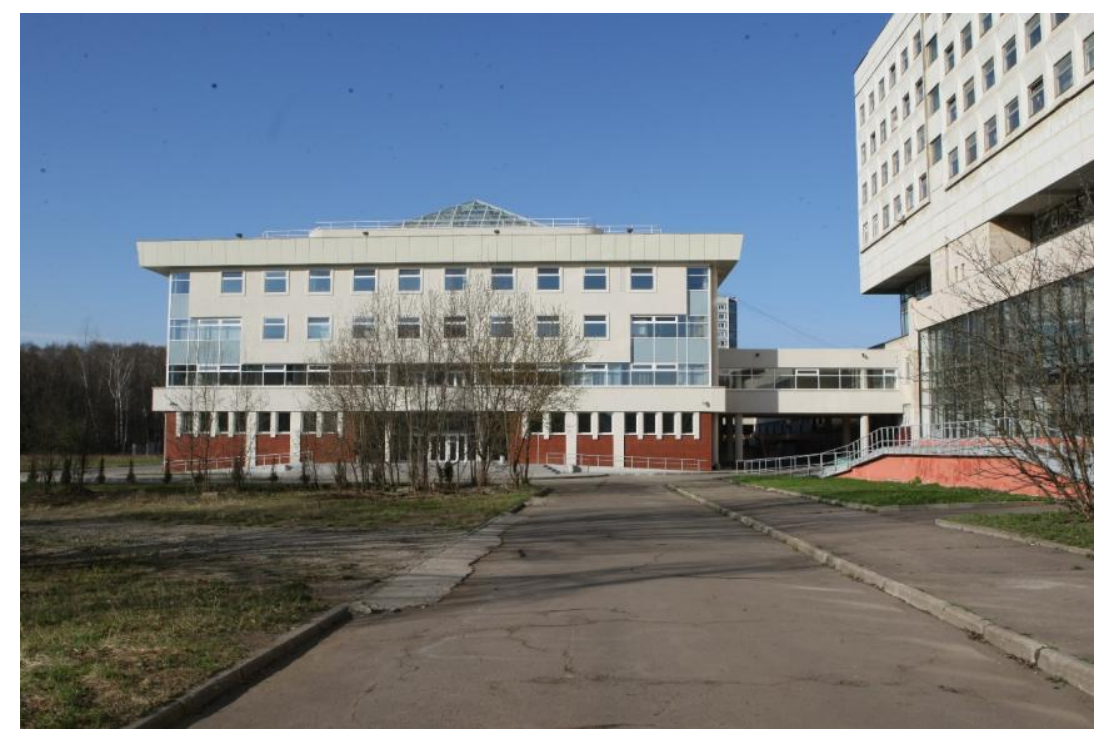

Figure 1. Educational Laboratory Building, equipped with energy-efficient automated control system.

\section{Method}

The system is based on the main-modular principle. The data from the end devices are transmitted to the control device modules (one module consists of up to 5 rooms), then the information is transferred to the storey controller, then to a central server SEC MGSU. The central server is physically consists of two servers - the first is subject to problems of operational management, the second is subordinate to the tasks of archiving and analytical processing data. It is controlled in real time. Access to the information management system is carried out on a local network of university, when you enter of appropriate access data. Through the information system interface available information on all the parameters controlled by the SEC MGSU, available setting values of the parameters of engineering systems and the assignment of rooms' microclimate parameters.

In addition to the above-described infrastructures in SEC MGSU also established laboratory facilities to carry out research projects activities with students and graduate students. Here are created 5 unique laboratories in various fields of building automation and energy saving. Laboratory equipment - proprietary research stands its own design. A wide range of features and options scaling of developed scientific equipment allows to use them in the work since the educational process of 3rd year Baccalaureate and ending with the preparation of doctoral theses.

Special attention in SEC MGSU is pad to practical application and promotion of energy-efficient solutions for the construction. Conducted in SEC MGSU experiments show payback of used improved energy efficiency technologies within 3-5 years. Thus, the undeniable is attraction of investment for the owner of real estate such technology introduction [4-12].

In 2015 began a new stage of development MGSU SEC associated with the use of BIM-technologies.

Information modelling of construction projects for today is one of the most effective tools to reduce the cost of design, construction, operation and disposal of buildings and structures. A look at the life cycle of construction projects as a continuous process makes it possible at the stage of concept development and design to take the necessary decisions to improve the efficiency of their operation, and recycling. At the same time the use of BIM-technology in the design process significantly speeds, reduces the cost and improves the quality of design process itself, contributing to the avoidance of errors, collisions and making it easier to verify compliance with regulatory requirements $[1-3,13]$.

Above applies primarily to construction projects, information model of which began to form in the early stages of the life cycle and "lived" with the object through all processes: the adjustment of design decisions, changes in design solutions in the construction, repair and overhaul, alterations, replacement 
of systems engineering equipment and so on. However, significantly improve the efficiency of existing buildings and structures is also possible through the creation of an information model of the object directly at the operation stage.

Creation of such a model in the first place, increases the efficiency of repair work, in large building complexes allows administering maintenance service work taking into account the current state of the elements of buildings, optimize engineering systems equipment.

An example of such an information model is implemented today in SEC MGSU. The model is based on three main blocks - architecture 3-d model, engineering simulation model systems and system of automated monitoring and control of engineering systems.

\section{Conclusion}

Merging into a single building information model allows these components to achieve the results described above and, in addition, harnessing simulation model of engineering systems, analyze the effectiveness of the use of new types of equipment before carrying out maintenance work associated with its replacement. Also, integration of a simulation model of engineering systems with a system of automated monitoring and control of engineering systems makes it possible to verify the modules of simulation model corresponding to the different types of equipment, including undergoing testing.

Thus, for today in the Moscow State University of Civil Engineering building has created a unique scientific and practical platform for development and testing of advanced technologies for construction and housing. To date, close to completing work on the creation of an information model of the operated building, designed to ensure the transition to a new level of maintenance of building.

\section{Acknowledgement}

This work was financially supported by the Ministry of Russian Education (state task \#2014/107)

\section{References}

[1] Volk, R., Stengel, J., Schultmann, F. Building Information Modeling (BIM) for existing buildings - Literature review and future needs (2014) Automation in Construction, 38, pp. 109-127.

[2] Wang, X., Chong, H.-Y. Setting new trends of integrated Building Information Modelling (BIM) for construction industry (2015) Construction Innovation, 15 (1), pp. 2-6.

[3] Shanmuganathan, S. BIM - A global consultant's perspective (2013) Structural Engineer, 91 (11), pp. 102-104.

[4] A.A.Volkov, D.E. Namiot, M.A. Shneps-Shneppe, On the tasks of creating an effective infrastructure for habitat. // International journal of open information technologies. - 2013. - V7 (1). - pp. 1-10.

[5] J Duffy,W Beckman, Thermal processes using solar energy. - M .: Mir, 1977.

[6] M.M. Brodach, Heat Energy optimization orientation and size of the building. // Proceedings of the Research Institute for Building Physics. M., 1987. The heat treatment and durability of buildings.

[7] P.P.Denisov, Influence index space-planning solutions building on the heat consumption. "Housing" 1981, №1.

[8] B.I. Giyasov, The impact of infrastructure development on the urban living environment // Vestnik MGSU. - 2012 - V4

[9] Volkov, A. General information models of intelligent building control systems: Scientific problem and hypothesis (2014) Advanced Materials Research, 838-841, pp. 2969-2972. 
[10] Volkov, A. General information models of intelligent building control systems: Basic concepts, determination and the reasoning (2014) Advanced Materials Research, 838-841, pp. 2973-2976.

[11] Volkov, A.A., Sedov, A.V., Chelyshkov, P.D. Modelling the thermal comfort of internal building spaces in social buildings (2014) Procedia Engineering, 91, pp. 362-367.

[12] Volkov, A., Chelyshkov, P., Sedov, A. Application of computer simulation to ensure comprehensive security of buildings (2013) Applied Mechanics and Materials, 409-410, pp. 1620-1623.

[13] Volkov, A., Sedov, A., Chelyshkov, P. Usage of building information modelling for evaluation of energy efficiency (2013) Applied Mechanics and Materials, 409-410, pp. 630-633. 